\title{
A Food Recall Case Study in Australia - Towards the Development of Food Safety Applications for Consumers
}

\author{
Adeola Bamgboje-Ayodele ${ }^{a^{*}}$, Leonie Ellis $^{\mathrm{a}}$, And Paul Turner ${ }^{\mathrm{a}}$ \\ ${ }^{\mathrm{a}}$ University of Tasmania, School of Engineering and ICT, Tasmania, Australia \\ ${ }^{*}$ Corresponding author \\ Adeola.Bamgboje@utas.edu.au \\ TEL: +61-3-6226-7530
}

Received: 13 May 2015; Published online: 18 April 2016

\begin{abstract}
Changes in consumer attitudes, behaviours and purchasing preferences towards different types of food highlight the increased demand for better quality information on safety, quality and provenance of food products and on sustainability of food production processes. These changes offer both new opportunities and risks for food producers who require mechanisms to better understand and respond to changing consumers' decision-making trends on food. In the area of food safety, investigation of consumer and producer responses during recall incidents provide an opportunity to holistically understand existing information flows and elicit user requirements necessary for the development of more effective consumer food safety applications.

This paper reports on a case study conducted with an Australian premium manufacturing company that experienced a food recall in 2014. The investigation confirms that current Australian food recall response mechanisms do not guarantee a closed loop of communication with all purchasers of a recalled product. It also highlights that producers still face difficulties in understanding how best to effectively understand and respond to different types of consumers. It emerges that recovery from a food incident relies on many factors including pre-existing brand reputation, effective information management, control mechanisms and supply chain partner response. From a consumer perspective, it is evident that consumers' responses are influenced by various factors that require sensitivity around the choice of information modality and information platform adopted to enhance communications during food recall. The paper highlights the need for further research into understanding consumer food safety behaviours post-purchase to improve the development of consumer food safety applications.
\end{abstract}

Keywords: Consumers; Decision-making; Food Recall; Information Technology

\section{Introduction}

For the Australian food industry and in particular, the premium food industry, changing consumer expectations, higher quality \& safety standards (Grunert, 2005), and the pervasiveness of mobile and social media (DPMC, 2012) have contributed to increased discussion on appropriate mechanisms for product traceability and for end-consumer engagement. While some businesses have embraced the opportunity to value-add with information (Stachowski, 2012), the multi-national structure of much global food production has led to some industry resistance to improved information transparency (Barker, 2014; Kearney, 2010). Despite these barriers, many food businesses and interested consumers continue to try to innovate to enhance the flow and quality of information on foods and food chains (Ruiz-Garcia, Steinberger, \& Rothmund, 2010). Many food businesses want 
to better understand how differences in consumer's characteristics influence the receipt and use of any information provided, and in-turn how this impacts the decisions that consumer's make during individual purchases of food types and brands. For firms producing premium products for niche markets, it becomes imperative to incorporate strategies that ensure brand differentiation through improved information transparency (Grunert, 2005) to gain and retain consumer confidence in their products.

As with other industry sectors, the adoption and use of mobile technology and social media are improving consumers' access to information (Heinonen, 2011). However, it remains much less clear what modes of information delivery, modes of interaction and levels of content complexity are most appropriate and/or effective for different types of consumers. One problem that provides an opportunity to investigate these concerns in detail relates to food safety and more specifically food recall incidents where timely, relevant and accurate information is not only important for the food business but critical for the safety and health of end-consumers.

This paper reports on the results of a case study conducted with an Australian premium food producer who experienced a food recall incident in 2014. The case study identifies challenges with current Australian food recall response mechanisms and reports on the factors that contribute to recovery from these recall incidents as well as the difficulties that food producers face in understanding and responding to different types of consumers about food safety.

\section{Food Recalls in Australia}

According to Food Standards Australia New Zealand (FSANZ, 2008), a food recall is an "action taken to remove from distribution, sale and consumption, food which may pose a health and safety risk to consumers". The two levels of recall that occur are trade recalls (not involving consumers) and consumer recalls. Between 2004 and 2014 Australia experienced 600 food recall incidents (ACCC, 2014). Specifically in relation to premium food products a number of recalls involved detection of contamination with Escherichia coli. This contaminant causes a wide range of clinical symptoms, including non-bloody diarrhoea, haemorrhagic colitis, and death (Kousta, Mataragas, Skandamis, \& Drosinos, 2010). During these recall incidents consumers were advised not to eat these products and to return them to the place of purchase for a full refund (ACCC, 2014). Under Australian law, primary producers and processors are required to maintain traceability records to support the easy identification and location of food products should issues, such as chemical contamination, presence of foreign matter, arise that require product recall (FSANZ, 2008).

An important aspect of any food recall involves information management, as supply chain stakeholders are required to disseminate information to government authorities and the general public in order to reduce the likelihood that affected products are consumed. Currently, this process is conducted through the use of newspapers, television, radio as well as the webpages of the businesses concerned and the Australian Competition and Consumer Commission. Whilst this "information-push" strategy is relatively effective in ensuring that potentially unsafe products are removed from distribution and retail outlets, the system does not extend to formal actions involving consumption and relies primarily on an implicit 'hope' that consumers who have purchased the products will learn of the recall and do not consume the product for which the recall action had been raised. Therefore, current recall response mechanisms do not guarantee a closed loop of communication with all purchasers of a recalled product. This makes it more difficult to accurately bench-mark the effectiveness of the current system and provides little insight into how consumers respond to any information disseminated through these mechanisms. For businesses too, merely performing their legal obligations are unlikely to be sufficient to mitigate risks, as the form, nature and information channel used will influence consumer confidence in their products and/or brands in different ways and amongst different types of consumers both during and after the recall (Verbeke \& Ward, 2006).

In the last 15 years, studies focusing on understanding consumer food safety knowledge, 
decision-making and food handling behaviours have proven to be productive areas of research (Ergönül, 2013; Tache \& Carpentier, 2014). More recently, researchers have also focused on how best to respond to consumer food safety challenges using information technologies to accommodate differences amongst consumers and their contexts of use. Increasingly there is interest in trying to develop techniques for selecting appropriate information modalities and information channels for enhancing communications about food safety as well as improving the design of consumer focused food safety applications.

\section{Consumers, Technology Adoption \& Use Food Safety}

A significant amount of research has been conducted in areas related to consumer behavior such as consumer decision making, consumer adoption and use of technology, consumer food purchase behavior, consumer food safety behavior as well as areas related to bridging gaps between the firm and the consumers such as knowledge management strategies, mobile application technologies, traceability technologies etc. (Kuttschreuter et al., 2014; Mayer \& Harrison, 2012). As this research context is multidisciplinary in nature, there is need to identify the gaps in relation to consumers' responses and decisions about information delivery mechanisms around post-purchase food safety.

Previous research (Bamgboje-Ayodele, Ellis, \& Turner, 2014) has highlighted that increasing numbers of premium food producers are now recognizing the need to optimize communication with end-consumers and to incorporate this into their knowledge management and business strategies. As discussed above, during food recall incidents current mechanisms do not guarantee a closed loop of communication with all purchasers of a recalled product. Consequently, consumers are faced with a considerable level of uncertainty about the safety of products in their possession, including whether the products have the potential to harm them and/or are being discarded unnecessarily thereby contributing to food wastage. For businesses, this consumer uncertainty presents ever higher risks to consumer confidence in their products and/or brands. As a result many premium producers are trying to enhance their understanding and ability to respond to end-consumers around food safety, quality and provenance.

A review of recent research literature into the use of information technology to improve consumer food safety identifies evidence that labels, information sheets, barcodes, 2D barcodes and RFID tags have been researched in relation to nutritional information but a number of gaps remain including detail on preferences of consumers in the use of QR codes and/or NFC tags with mobile devices (Chrysochou, Chryssochoidis, \& Kehagia, 2009). There is however some evidence (Voordouw et al., 2011) suggesting that some consumers' preference for the use of labels and information sheets is linked to their educational and technological backgrounds, although it is unclear whether these insights are culturally constrained or can be applied to Australian consumers.

Based on the results of the study conducted by Reid, Li, Bruwer, and Grunert (2001), it appears that application of food related lifestyle consumer categorization is also an important dimension. Similarly, Van Rijswijk and Frewer (2012) have emphasized the importance of consumer categorization as a pre-requisite for determining the influence of any information delivery platform on different types of consumers. Solomon, Polegato, and Zaichkowsky (2009) have also argued that the form in which information is presented is highly important, but it is evident that there is still a need for considerable research to investigate the influence of textual, verbal, visual and integrated information within the appropriate information delivery platforms on different consumers decision-making around food safety.

In other domains, rapid improvements in technology have led consumers to access even more information on products to support their purchasing decisions (Murray, Liang, \& Haeubl, 2010). For example; in banking, online shopping (Yang \& Forney, 2013), and personal ICT use; including social media (Thong, Venkatesh, Xu, Hong, \& Tam, 2011). What is less clear is what happens to consumers' post-purchase of products and services when consumption actually occurs. Murray 
Developing a Food Safety Application for Australian Consumers $\mid 87$

et al. (2010) defined assistive technologies as "a group of tools that help consumers make better choices, with less effort, when faced with daunting data and limited time". While the term, encapsulates the different uses of technologies during consumer decision making, it appears inadequate for the food recall situation where consumers are usually not faced with too much data but rather too little or none. This highlights that during food recall, there is need to afford consumers the opportunity to 'pull information' directly from the business concerned, not just to alleviate consumers' uncertainties about the safety of the food but to support retention of their confidence in the product/brand.

Other researchers have also explored consumer perceptions about the use of internal tag technology involving insertion of 'internal tags' into food and natural health products (Lilavanichakul \& Boecker, 2013). However, to date, these approaches have been primarily focused on preprogrammed information focused on information about nutrition, producer and country of origin. In a dynamic food recall situation, it remains unclear how they might be deployed and how they would influence consumers' decision-making about the safety of a food product post-purchase. Dwivedi, Williams, Lal, and Mustafee (2010) reviewed research studies into consumer technology adoption and use. This review highlighted a number of key factors based on the Technology Acceptance Model (TAM) and its derivations such as design quality of the system, privacy, experiential quality, perceived usefulness, complexity, and perceived enjoyment (Liao, Chang, \& Chang, 2011). Some other researchers have focused on the Unified Theory of User Acceptance and Use of Technology (UTAUT) model that considers the purpose of technology use (Thong et al., 2011) and technology anxiety (Yang \& Forney, 2013) as key factors influencing consumers' adoption and use of technology. However, the incorporation of Media Richness Theory (MRT) into an investigation of consumers' motives for their choice of complaint channel (Robertson, 2012) was interesting and could be valuable to the context defined in this study.

Similarly, while research work on usability testing deals with ensuring that products meet the actual needs of the intended audience - in this case the consumers (Rogers, Preece, \& Sharp, 2011) there is limited evidence of these approaches being used for food consumers. Indeed, the focus of many of these studies has largely been on the adoption and expected use of these technologies using a 'one-size fits all' approach. There have been fewer studies trying to focus on their design and implementation in a way that facilitates intended use by different types of consumers.

More importantly, this brief review of multidisciplinary research on consumers, technology adoption \& use and the challenge of food safety highlights the fact that numerous gaps remain in our knowledge. It is unclear how variable consumers understanding of information acquired through the use of technology is. Similarly, their responses based on individual socio-economic, educational and cultural contexts is also unclear. In this context, this research paper aims to investigate and analyze mechanisms for enhancing consumer-focused technology-based information delivery mechanisms and contemporary understanding of how the attributes of different consumers influence their responses and decisions around food safety post-purchase. The next section describes the methodology deployed for the conduct of the case study.

\section{A Food Recall Case Study}

This research has been approved by the Tasmanian Social Sciences Human Research Ethics (H14010). The approach utilised an interpretive research philosophy and deployed a mixedmethod design structured in three overlapping phases. Phase 1 involved the carrying out case studies on the business-focused aspect of the study. Phase 2 involves the development and evaluation of a range of smart phone compatible designs (textual, visual, verbal, integrated) from the consumers' perspective. Phase 3 involved the development and evaluation of a theoretical model for optimizing information delivery to consumers which will be iteratively refined based on further interactions with food firms and consumers.

To date, one case study with an Australian premium food firm has been completed and will be 
discussed in more detail below. This case has already contributed important insights into the business responses to food recall situations and the associated information and knowledge flows. Phase 1 also involved interaction with premium food consumers whose perspectives and preferences on food safety were initially obtained using a survey instrument based on best-worst scaling experiments. This experiment helped to identify attributes that influence food purchase decisions as well as post-purchase safety behaviour in order to provide insights into the contextual focus of the mobile application that will be developed. Combined, the firm and consumer data generated insight into current food quality and safety information provided to consumers during the recall of a perishable product; consumer preferences and experiences of this information; and their decision-making during these recall incidents. Furthermore, the final research activity in Phase 1 involved scenario-based focus group sessions to provide insights for the design of the mobile phone application d developed in Phase 2 of the study. Therefore, Phase 1 encompassed an in-depth qualitative (semi-structured interview) investigation into the firm's perspective followed by a quantitative investigation (a nation-wide survey) into consumers' perspective and is finished off by generating more in-depth insights into consumers' perception through another qualitative study (focus groups).

Following data collection, the case study was constructed through thematic analysis to identify themes in the data. The categories used to create the themes were formed inductively to gather insights from the data itself (Ezzy, 2013). Thematic analysis helps form a holistic view of the case while ensuring all areas of interest are covered (Braun \& Clarke, 2006). This approach supports exploration of issues that might not have been identified at the outset of the study. According to Ezzy (2013), it has been argued that the procedure of coding can help researchers expand beyond boundaries of preexisting theory while revealing individual interpretations. Therefore, the information gathering and inductive process characteristics of thematic analysis, made it a valid approach for this research. The analysis was conducted at three conceptual coding levels; open, axial and final themes. The development of the open codes was done repetitively before the final open codes were abstracted from the second stage of the analysis, axial coding. At the axial code level, the detail of analysis was made robust and was enriched by the iterative nature of the development of the code. The final level of the data analysis involved looking at the attributes of each axial code to create the final level themes.

\section{Results: Discussion and Interpretation}

This section presents the results of the initial investigation and provides a discussion and interpretation based on the initial food recall case study. The business that was the focus of this case study was an Australian food firm producing premium products within the dairy food group and was selected due to a recently experienced food recall incident. Due to the sensitivity of the context of the investigation and the confidentiality agreement with this business, further details about the firm cannot be provided with regard to business location/state and product name. It can however be revealed that the recall was due to Escherichia coli (E.coli) contamination. The analysis of the data produced 419 open codes, 116 axial codes and 4 final themes. The themes are; firm-focused reactions; firm's understanding of consumer reactions; information dissemination actions and reactions; and governmentrelated influences. Based on these themes, the results from this case study were structured in four sections, one for each theme. It should be noted that because there were no major systematic differences amongst the participants, the results discussed below apply to all participants as a single group unless otherwise stated.

\section{$5.1 \quad$ Firm-focused Reactions}

This section discusses and interprets the actions the firm took when the recall occurred; the cause of the recall situation; the impact of the recall; and the firm's perceived mode of recovering from the recall. Firstly, once the firm became notified about the compromise in the safety of the products, the firm took action to implement the 
Developing a Food Safety Application for Australian Consumers 89

voluntary recall process. The actions included: identifying the boundaries of contamination; contacting the health department (FSANZ) and contacting each wholesaler and retailer. While the actions may seem impeccable, it showed the gap in the current recall mechanisms established by the government. The firm had indeed accomplished its legal obligation to ensure that the affected products were not distributed or sold but the firm was not obliged to follow through to ensure the affected products were not consumed. Therefore, it is arguable that the primary aim of a food recall as defined by FSANZ is not necessarily being achieved, or at the very least, it is difficult to assess the extent to which any individual recall is $100 \%$ effective in relation to product consumption.

Secondly, the firm was able to identify the cause of the recall within the firm. This was attributed to human error, which led to random contamination. The firm believed the situation was caused by a staff member who was not following procedures.

"It's reasonably clear what happened. It was a person not following instructions and really not following the induction process, not following procedures."

However, it appeared that a knowledge management issue was indeed the cause of the recall, as there was knowledge loss, four weeks before the recall occurred. This suggested that knowledge loss can directly contribute to recall situations within a food business.

"One of the other things that is quite interesting with my staff recently... I had my supervisor retire, $[4$ weeks to the recall date] and I had one of my excellent workers leave, probably because she wasn't happy with the appointment of the next supervisor. So that was interesting; because that key person may be its part of the reasons why the situation occurred."

Furthermore, the findings suggest that the recall indeed impacted the firm negatively due to loss of revenue, employee loss, but more importantly, the loss of consumer confidence. One interesting point concerned the loss of good products as the firm currently has no traceability system that can efficiently narrow down the boundaries of contamination. Thus, this aligns with the argument by Saltini and Akkerman (2012) that the use of traceability systems can indeed help in avoiding unclear liabilities during product recalls.

\begin{abstract}
"We've lost 25 or $27 \%$ of our annual revenue now. That's sort of what we are judging it on, plus we had to throw out all the good [products]."
\end{abstract}

In addition to the impact of the recall on the firm, the situation influenced the standing and market dynamics of the firm which was the loss of shelf space in retail stores which had the potential to lead to the loss of loyal consumers despite the level of confidence the firm has built over time.

"So the major problem is the shelf space where someone else might have taken ... So I think ... you may have lost those customers forever."

Although the firm was still recovering from the recall, as at the time this case study was conducted, some insights were generated into the firm's perceived mode of recovering from a food recall. The key constructs they relied upon were: reputation, transparency and experience. However, it appears these constructs were contingent upon time as a factor.

Therefore, this has provided some insights to the recall actions taken by the firm; the cause of the recall situation; the impact of the recall; and the firm's perceived mode of recovering from a recall. Thus, gaps of the current food recall system in Australia were revealed, as discussed in Section 2 while showing the disadvantages associated with not having a food traceability system within a supply chain. 


\section{$5.2 \quad$ Firm's Understanding of Consumer Reactions}

This section discusses and interprets the perception of the firm in relation to consumers' reaction and perceptions concerning the recall incident. There was mixed reactions to the way consumer behavior was perceived, as some of the respondents believed that the consumers did not worry about the recall incident, while some others argued otherwise.

"As I said, each week, people wanted the product, they were asking for it; even though it was a product that had been recalled." - Husband

"One customer mentioned it and said literally that ... oh you're back opened, I said yeah; about the recall...oh that was a nightmare. [The product] is ok now? I said yep, everything is good. So that was a customer who was regular." - Sales rep

"So he would have probably seen in the papers and read it and made the inquiry. May be [my husband's] comment was not the right one. It wasn't right because at the top of their minds, there's a problem with the product." Owner

The firm however suggested that despite the incidence and the inconvenience it had caused some consumers, the quality of their product may well restore some of the lost consumers; thus portraying product quality as one of the factors that can facilitate recall recovery.

"... there is that person out there, who was inconvenienced but would come back because they believe in the quality of our product."

Therefore, this has provided some insights to the perception of the firm in relation to consumers' reaction and views concerning the recall incident. Though the incidence influences consumers negatively, an argument was however put forward for an investigation into the efficacy of product quality on recovering from a recall.

\subsection{Government-Related Influences}

This section discusses and interprets the perception of the firm in relation to the government related influences on the recall incident. These include the occurrence of the federal budget and public holidays which could have influenced the sale of products at such period, thus distorting the actual impact of the recall.

"The other thing is that during that period there has been the federal budget ...Certainly since the first few weeks since then [occurrence of federal budget], we haven't had much pay cheque."

"The recall was just before a public holiday. And so the health department was very keen because it was a public holiday, they felt that that was a good reason to just work really quickly as well."

Thus, the firm believes that the federal budget appears to have actually influenced the impact of the recall negatively, while the public holiday could have influenced the incident positively. On the part of the government, working quickly during a public holiday was probably helpful because more consumers could be easily exposed to potentially unsafe products while attending public functions or casual dinners and entertainment. On the part of the firm, this was probably helpful because earnest completion of the voluntary recall process facilitates the swift commencement of the recovery process.

\subsection{Information Dissemination - Actions and Reactions}

This section discusses and interprets issues concerning information dissemination between the firm and the consumer before, during and after the recall incident. Information dissemination is concerned with targeting the right consumer 
Developing a Food Safety Application for Australian Consumers |91

with the right information through the right delivery medium or channel. An interesting phenomenon which was noted relates to the recognition of the possibility of information mismatch. This means targeting the wrong consumer with the right information and vice versa.

“... the media releases for the recall were placed in a lot of country papers and we don't distribute in the country and so I think it's interesting what happened, people saw the recall notice and got thinking I can now get [X-product] in [W-location] and rang and said where is it?"

While the situation in the excerpt above generated a positive outcome, that may not be the case in all circumstances. Therefore, information dissemination is not just about utilizing the right information delivery platform, but it is about ensuring that the right information gets to the right consumers.

Furthermore, the limitations associated with focusing on a single mode of information delivery platform were demonstrated and therefore advocate for the use of a variety of platforms in order to cover a broad population of consumers. One of the problems faced with labels include space constraints.

"On our product, we say it is "handmade in the [AAA] hills"... because I didn't want to clutter this up. Again, that information is "from local [raw material], produced by $[\mathrm{XX}]$, product of Australia, hand-made, Artisan" but you can only do "made in the [AAA] hills", so there's only so much to do."

In addition, the information delivery problems shown were not limited to the labels and that technology based platforms are not sufficient by themselves.

“... look at 18 to 35 year olds [who] are very interested in food and they are smart phone users. Tick. Then you've got your 36 to 50 . Tick. Then you've got 50 to 60 year olds and ... 60+ and that's not smart phone, that's not website. So you still need to have the story because ... I still want people in here (50-60) and in here (60+) to pick this up and to say oh...ok, so this person has been making [this product] for 15 years."

Therefore, it appears that firms are better positioned when they utilize multiple information delivery platforms to ensure broad coverage of the consumer base. Thus, there is evidence for a need to investigate how best to respond to consumer food safety challenges using information technologies to accommodate differences amongst consumers and their contexts of use. This leads to broader discussions about communicating with consumers on food safety not just during a recall incident; but more broadly postpurchase.

\subsection{Preliminary Outcomes}

The findings of the first case study of the research are viewed from two perspectives; producer perspective and consumer perspective. For producers, it emerges that recovery from a food incident relies on a number of factors including pre-existing brand reputation, effective information management, control mechanisms and supply chain partner response. As earlier argued about the existence of some industry resistance to improved information transparency, findings revealed some information restrictions that occurred within the firm's supply chain. In this case, the supply chain partners do not allow information sheets on shelves; thus, drawing more attention towards the delivery of information through technology-based channels.

From a consumer perspective, it is evident that consumers' responses are influenced by a wide range of factors that require sensitivity in terms of the choice of information modality and information platform adopted to enhance communications during food recall. There are two instances demonstrating this. Firstly, while the firm demonstrates authenticity as a value, which 
92 Bamgboje-Ayodele et al.

Table 1: A summary of the Preliminary Outcomes

\begin{tabular}{lll}
\hline $\begin{array}{l}\text { Context based on } \\
\text { the Case Study }\end{array}$ & $\begin{array}{l}\text { Factors influencing recovery } \\
\text { from recall incident }\end{array}$ & $\begin{array}{l}\text { Information related factors } \\
\text { influencing consumer responses }\end{array}$ \\
\hline Producer's Perspective & $\begin{array}{l}\text { Pre-existing brand reputation } \\
\text { Control Mechanisms } \\
\text { Supply Chain partner response }\end{array}$ & \\
\hline $\begin{array}{l}\text { Bridging the Gap between } \\
\text { producer and consumer }\end{array}$ & Effective Information management & $\begin{array}{l}\text { Multiplicity of information } \\
\text { delivery platform } \\
\text { Understanding the diversity } \\
\text { of consumer }\end{array}$ \\
\hline $\begin{array}{l}\text { Consumer's Perspective } \\
\text { (based on firm's understanding) }\end{array}$ & & $\begin{array}{l}\text { Choice of information modality } \\
\text { Choice of information platform }\end{array}$ \\
\hline
\end{tabular}

translates to provenance, from the consumers' point of view, it is however limited by the amount of textual information that can be placed on labels. Secondly, as the firm has recently experienced a recall situation, it became skeptical about updating end consumers regarding the safety status of their food products after the problem had been rectified in order to avoid negative perception. Perhaps, this was as a result of the media involvement. This raises questions about the appropriateness of the information platform for communicating with consumers about sensitive issues as the firm wanted to update the consumers but could not do so. Table 1 shows a summary of the preliminary findings generated from the case study.

Therefore, these findings support the need for investigating how best to respond to consumer food safety challenges using information technologies to accommodate differences amongst consumers and their contexts of use. Thus, leading to the development of techniques; for selecting appropriate information modalities and information channels; for enhancing communications about food safety and improving the design of consumer focused food safety applications.

\section{Conclusions}

This research is part of an investigation into how information technologies, applications and services can be developed and deployed to better support businesses and end-consumers making more informed decisions about premium food products $^{1}$ and its safety. This paper has identified challenges with current Australian food recall response mechanisms and reported on the factors that contribute to recovery from these recall incidents as well as the difficulties that food producers face in understanding and responding to different types of consumers about food safety. Moving forward, this leads to insights about communicating with consumers on food safety not just during a recall incident; but more broadly post-purchase.

Future work will involve the completion of the other 9 case studies in order to establish strong insights from the firm-focused aspect of Phase 1. While this is ongoing, the perspectives and preferences of premium food consumers on food safety will be obtained using a survey instrument based on best-worst scaling experiments. Following this, we will progress to Phase 2, where we will develop a range of smart phone compatible information designs for each information platforms on different types of consumers. The platforms will be evaluated and result in the development of the theoretical optimization model. Finally, in Phase 3, we will evaluate and iteratively refine the model based on practical insights from further investigations.

\footnotetext{
${ }^{1}$ Pathways to Market: http://www.sense-t.org.au/ projects/pathways-to-market
} 
Developing a Food Safety Application for Australian Consumers $\mid 93$

\section{References}

ACCC. (2014). Product and safety recalls australia - dairy and eggs. Retrieved 21st January 2014. Retrieved from http://www . recalls . gov . au / content / index . phtml / itemId/952826

Bamgboje-Ayodele, A., Ellis, L., \& Turner, P. (2014). Identifying key research challenges in investigating knowledge optimization strategies in perishable food chains. In ICICKM2014-Proceedings of the 11th International Conference on Intellectual Capital, Knowledge Management and Organisational Learning: ICICKM2014 (p. 48). Academic Conferences and Publishing International Limited.

Barker, D. (2014). Transatlantic Trade and Investment Partnership (TTIP) - Impacts on Food and Farming. Trade Matters. Retrieved from http : / / issuu . com / centerforfoodsafety / docs / cfs_trade_ matters

Braun, V. \& Clarke, V. (2006). Using thematic analysis in psychology. Qualitative research in psychology, 3(2), 77-101.

Chrysochou, P., Chryssochoidis, G., \& Kehagia, O. (2009, December). Traceability information carriers. the technology backgrounds and consumers' perceptions of the technological solutions. Appetite, 53(3), 322-331. doi:10.1016/j.appet.2009.07.011

DPMC. (2012). Australia in the asian century. Canberra: Retrieved 22nd December 2013.

Dwivedi, Y. K., Williams, M. D., Lal, B., \& Mustafee, N. (2010). An analysis of literature on consumer adoption and diffusion of information system/information technology/information and communication technology. International Journal of Electronic Government Research (IJEGR), 6(4), 5873.

Ergönül, B. (2013). Consumer awareness and perception to food safety: a consumer analysis. Food control, 32(2), 461-471.

Ezzy, D. (2013). Qualitative analysis. Routledge. FSANZ. (2008). Food Industry Recall Protocol - A guide to conducting a food recall and writing a food. Recall plan. Retrieved 14th Feb 2014. Retrieved from http : / / www . foodstandards . gov . au / industry / foodrecalls / firp / documents / Food\%20Recall_WEB.pdf

Grunert, K. G. (2005). Food quality and safety: consumer perception and demand. European Review of Agricultural Economics, 32(3), 369-391. 11th International Congress of the European-Association-ofAgricultural-Economists (EAAE), Copenhagen, DENMARK, AUG 24-27, 2005. doi:10.1093/eurrag/jbi011

Heinonen, K. (2011). Consumer activity in social media: managerial approaches to consumers' social media behavior. Journal of Consumer Behaviour, 10(6, SI), 356-364. doi:10.1002/cb.376

Kearney, J. (2010). Food consumption trends and drivers. Philosophical Transactions of the Royal Society B-biological Sciences, 365(1554), 2793-2807. doi:10.1098/rstb. 2010.0149

Kousta, M., Mataragas, M., Skandamis, P., \& Drosinos, E. H. (2010). Prevalence and sources of cheese contamination with pathogens at farm and processing levels. Food Control, 21 (6), 805-815. doi:10.1016/ j.foodcont.2009.11.015

Kuttschreuter, M., Rutsaert, P., Hilverda, F., Regan, A., Barnett, J., \& Verbeke, W. (2014). Seeking information about foodrelated risks: the contribution of social media. Food Quality and Preference, 3\%, 10 18. doi:10.1016/j.foodqual.2014.04.006

Liao, P.-A., Chang, H.-H., \& Chang, C.-Y. (2011). Why is the food traceability system unsuccessful in taiwan? empirical evidence from a national survey of fruit and vegetable farmers. Food Policy, 36 (5), 686693. doi:10.1016/j.foodpol.2011.06.010

Lilavanichakul, A. \& Boecker, A. (2013). Consumer acceptance of a new traceability technology: a discrete choice application to ontario ginseng. International Food and Agribusiness Management Review, 16(4), 25-49.

Mayer, A. B. \& Harrison, J. A. (2012). The use of online focus groups to design an online food safety education intervention. Journal of Food Science Education, 11(4), 47-51. doi:10.1111/j.1541-4329.2012.00145.x 
Murray, K. B., Liang, J., \& Haeubl, G. (2010). Act 2.0: the next generation of assistive consumer technology research. Internet $R e$ search, 20(3), 232-254.

Reid, M., Li, E., Bruwer, J., \& Grunert, K. (2001). Food-related lifestyles in a crosscultural context. Journal of Food Products Marketing, 7(4), 57-75. doi:10.1300/ J038v07n04\_05. eprint: http://dx.doi.org/ 10.1300/J038v07n04_05

Robertson, N. (2012). Self-service technology complaint channel choice exploring consumers' motives. Managing Service Quality, 22(2), 145-164. doi:10.1108/ 09604521211218963

Rogers, Y., Preece, J., \& Sharp, H. (2011). Interaction design : beyond human-computer interaction (3rd ed.) Chichester, West Sussex: J. Wiley \& Sons.

Ruiz-Garcia, L., Steinberger, G., \& Rothmund, M. (2010). A model and prototype implementation for tracking and tracing agricultural batch products along the food chain. Food Control, 21 (2), 112-121. doi:10.1016/ j.foodcont.2008.12.003

Saltini, R. \& Akkerman, R. (2012). Testing improvements in the chocolate traceability system: impact on product recalls and production efficiency. Food Control, 23(1), 221-226. doi:10.1016/j.foodcont.2011.07. 015

Solomon, M. R., Polegato, R., \& Zaichkowsky, J. L. (2009). Consumer behavior: buying, having, and being. Upper Saddle River, NJ: Pearson Prentice Hall.

Stachowski, C. A. (2012). The niche marketing strategy in internationally-oriented small and medium enterprises: a literature review and lessons for new zealand. Small Enterprise Research, 19(2), 96-112.

Tache, J. \& Carpentier, B. (2014). Hygiene in the home kitchen: changes in behaviour and impact of key microbiological hazard control measures. Food Control, 35(1), 392400. doi:10.1016/j.foodcont.2013.07.026

Thong, J. Y. L., Venkatesh, V., Xu, X., Hong, S.-J., \& Tam, K. Y. (2011). Consumer acceptance of personal information and communication technology services. IEEE Transactions on Engineering Management,
58(4), 613-625. doi:10.1109/TEM . 2010. 2058851

Van Rijswijk, W. \& Frewer, L. J. (2012). Consumer needs and requirements for food and ingredient traceability information. International Journal of Consumer Studies, 36(3), 282-290. doi:10.1111/j.1470-6431. 2011.01001.x

Verbeke, W. \& Ward, R. W. (2006). Consumer interest in information cues denoting quality, traceability and origin: an application of ordered probit models to beef labels. Food Quality and Preference, 17(6), 453467. doi:10.1016/j.foodqual.2005.05.010

Voordouw, J., Cornelisse-Vermaat, J. R., Pfaff, S., Antonides, G., Niemietz, D., Linardakis, M., .. Frewer, L. J. (2011). Preferred information strategies for food allergic consumers. a study in germany, greece, and the netherlands. Food Quality and Preference, 22(4), 384-390. doi:10 .1016/j. foodqual. 2011.01.009

Yang, K. \& Forney, J. C. (2013). The moderating role of consumer technology anxiety in mobile shopping adoption: differential effects of facilitating conditions and social influences. Journal of Electronic Commerce Research, 14(4), 334-347. 